\title{
Frost Durability and Strength of Concrete Prepared with Crushed Sand of Different Characteristics
}

\author{
Ming-kai Zhou, ${ }^{1}$ Zhan-ao Liu, ${ }^{1,2}$ and Xiao Chen ${ }^{1}$ \\ ${ }^{1}$ State Key Laboratory of Silicate Materials for Architectures, Wuhan University of Technology, Wuhan 430070, China \\ ${ }^{2}$ China Three Gorges Construction Management Co. Ltd., China Three Gorges Corporation, Chengdu 610041, China
}

Correspondence should be addressed to Zhan-ao Liu; liuzhanao701@163.com

Received 29 March 2016; Revised 30 May 2016; Accepted 7 June 2016

Academic Editor: Antônio G. de Lima

Copyright (C) 2016 Ming-kai Zhou et al. This is an open access article distributed under the Creative Commons Attribution License, which permits unrestricted use, distribution, and reproduction in any medium, provided the original work is properly cited.

\begin{abstract}
The influences of fines content, methylene blue (MB) value, and lithology of crushed sand (CS) on frost durability and strength of concrete were investigated, and the frost durability and strength of crushed sand concrete (CSC) and river sand concrete (RSC) were compared. The results show that inclusion of fines improves CSC compressive strength and reduces frost durability of C30 CSC when fines content reaches $10 \%$, whereas it has little negative influence on frost durability of C60 CSC. Increasing MB value does not negatively affect compressive strength of C30 CSC but decreases compressive strength of C60 CSC and frost durability of CSC, and the reduction is more pronounced when $\mathrm{MB}$ value exceeds 1.0. Lithology has no prominent influence on frost durability and compressive strength of CSC within the lithologies (dolomite, limestone, granite, basalt, and quartz) studied. Though compressive strength of CSC is a little higher than RSC under equal water to cement ratio, frost durability of CSC is no better than RSC especially for C30 CSC, and air-entraining agent is suggested for enhancing frost durability of C30 CSC exposed to freezing environment.
\end{abstract}

\section{Introduction}

Fine aggregate is a necessary raw material for making concrete, and its characteristics can impact concrete properties from workability to strength and durability. In developing countries where infrastructure constructions are massively needed like China, growing depletion and expansive cost of river sand (RS) have resulted in extensive application of CS. CS refers to fine particles finer than $4.75 \mathrm{~mm}$ produced by rock crushing. Generally speaking, CS particles are more angular and much tougher when compared with RS particles and particularly contain $10-20 \%$ of fines which are finer than $75 \mu \mathrm{m}$. These fines are likely to be contaminated by clay in the field and the presence of clay can be detected by MB value $[1,2]$.

A number of researches have been done on properties of CSC so far. It has been established that qualified concrete with satisfactory strength and durability can successfully be prepared using CS [3-5]. At a given water to cement (W/C) ratio, concrete made with CS often presents higher water demand and poorer workability than corresponding concrete made with RS, yet this negative effect can be offset by using high range water reducer or mineral admixture. Additionally, coarse texture strengthens the bonding between sand particle and cement paste, and the fines fill in the voids in cement paste to generate a denser matrix, which makes CSC have relatively higher strength and permeability resistance than RSC [6-8].

Properties of CS are greatly affected by parent rock and crushing technology $[9,10]$. Therefore, various CS may differ in parent rock lithology, fines content, and the amount of clay in sand, and it is recognized that these characteristics can affect both fresh and hardened properties of concrete. However, relevant researches are concentrated on mechanical or permeability properties of crushed limestone sand concrete $[3,11,12]$, and effects of such CS characteristics on property of CSC, especially frost durability, have been little investigated yet.

Therefore, this research reports an investigation on the effects of CS characteristics on frost durability of low- and high-strength CSC. In the study, frost durability of CSC was examined using the rapid freezing-thawing (FT) method and the test results were compared with those of RSC. The compressive strength of CSC was also investigated. Experimental 
TABLE 1: Physical properties of used cement.

\begin{tabular}{|c|c|c|c|c|c|c|c|}
\hline \multirow{2}{*}{ Density $\left(\mathrm{g} / \mathrm{cm}^{3}\right)$} & \multirow{2}{*}{$\begin{array}{c}\text { Standard } \\
\text { consistency (\%) }\end{array}$} & \multicolumn{2}{|c|}{ Setting time (min) } & \multicolumn{2}{|c|}{ Flexural strength $(\mathrm{MPa})$} & \multicolumn{2}{|c|}{ Compressive strength $(\mathrm{MPa})$} \\
\hline & & Initial & Final & $3 \mathrm{~d}$ & $28 \mathrm{~d}$ & $3 \mathrm{~d}$ & $28 \mathrm{~d}$ \\
\hline 3.13 & 27.0 & 125 & 190 & 6.8 & 9.3 & 30.3 & 51.2 \\
\hline
\end{tabular}

TABle 2: Properties of used fine aggregates.

\begin{tabular}{lcccccc}
\hline Lithology & $\begin{array}{c}\text { Apparent } \\
\text { density }\left(\mathrm{kg} / \mathrm{m}^{3}\right)\end{array}$ & $\begin{array}{c}\text { Crushing } \\
\text { value }(\%)\end{array}$ & $\begin{array}{c}\text { Void ratio } \\
(\%)\end{array}$ & $\begin{array}{c}\text { Fineness } \\
\text { modulus }\end{array}$ & $\begin{array}{c}\text { Water } \\
\text { absorption (\%) }\end{array}$ & Main mineral composition \\
\hline RS & 2630 & 12.4 & 36.0 & 2.81 & 0.53 & Quartz \\
DL & 2837 & 23.2 & 44.5 & 3.15 & 0.78 & Dolomite \\
LS & 2667 & 24.2 & 40.6 & 3.17 & 0.80 & Limestone \\
GR & 2650 & 18.7 & 42.7 & 3.17 & 0.87 & Quartz, sanidine, mica \\
BA & 2895 & 19.7 & 45.3 & 3.24 & 0.96 & Augite, anorthite \\
QZ & 2657 & 21.3 & 42.3 & 3.08 & 1.07 & Quartz, albite \\
\hline
\end{tabular}

${ }^{*}$ Grading of used CS was adjusted by means of sieving to obtain fineness of around 3.1.

results of this research can verify crucial factors affecting frost durability of CSC and provide technical guidance for application of CSC in cold regions.

\section{Experimental Program}

2.1. Materials. The cement used was 42.5 -grade ordinary Portland cement and its physical properties were displayed in Table 1. The fine aggregates were washed and consisted of a RS and five CSs of different lithologies, including dolomite (DL), limestone (LS), granite (GR), basalt (BA), and quartz (QZ). The properties of fine aggregate were shown in Table 2. The coarse aggregate (CA) was continuous grading crushed stone with a maximum grain size of $26.5 \mathrm{~mm}$, and its apparent density and crushing value were $2731 \mathrm{~kg} / \mathrm{m}^{3}$ and $10.7 \%$, respectively. The fines (density $2.89 \mathrm{~g} / \mathrm{cm}^{3}$, blain surface area $335.4 \mathrm{~m}^{2} / \mathrm{kg}$ ) were prepared by grinding washed CS in a ball mill. The clay (density $2.05 \mathrm{~g} / \mathrm{cm}^{3}$, blain surface area $417.8 \mathrm{~m}^{2} / \mathrm{kg}$ ) was obtained from a mining company. The water reducer (WR) was a high range polycarboxylate superplasticizer (solid content $39 \%$, density $1.07 \mathrm{~g} / \mathrm{cm}^{3}$ ), which is in conformity with Chinese industry standard JG/T 223-2007 [13].

2.2. Test Methods. Crushing value of aggregates was determined according to JTG E42-2005 [14]. Compressive strength of concrete was tested on $150 \mathrm{~mm}$ cubes in accordance with JTG E30-2005 [15]. Water absorption of concrete was measured on $100 \mathrm{~mm}$ cubes in compliance with ASTM C64213 [16]. Frost durability of concrete was tested on $100 \times$ $100 \times 400 \mathrm{~mm}$ prisms following "the rapid FT method" according to GB/T 50082-2008 [17]. The prisms specimen was kept for 28 days of wet curing and then cycled within a temperature of $-18^{\circ} \mathrm{C}$ to $5^{\circ} \mathrm{C}$ in a FT apparatus at an average rate of 8 cycles per day. The fundamental transverse frequency was recorded every 25 and 50 cycles for specimens of C30 and C60 concrete, respectively. The durability factor (DF) is determined according to the following expression:

$$
\mathrm{DF}=E_{r} \times \frac{N}{300}
$$

where $E_{r}$ is the relative dynamic modulus of elasticity at $N$ cycles (\%) and $N$ is the number of cycles at which $E_{r}$ reaches $60 \%$ for stopping the test or the specified cycle number of 300 at which the test is to be terminated.

The relative dynamic modulus of elasticity $E_{r}$ is determined according to the expression below:

$$
E_{r, n}=\left(\frac{f_{n}}{f_{0}}\right)^{2} \times 100,
$$

where $E_{r, n}$ is the relative dynamic modulus of elasticity after $n$ cycles of freezing and thawing (\%); $f_{n}$ is the fundamental frequency after $n$ cycles of FT (Hz); and $f_{0}$ is the fundamental frequency before FT cycle $(\mathrm{Hz})$.

\section{Results and Discussion}

3.1. Influence of Fines Content of CS on Strength and Frost Durability. Fines were incorporated in concrete as replacement of sand at variable contents, and the mix proportions of the influence of fines content on concrete frost durability and strengths are shown in Table 3.

The data in Table 3 show that compressive strengths of C30 CSC gradually increase with increasing fines content from 5 to $20 \%$, and the maximum $3 \mathrm{~d}$ and $28 \mathrm{~d}$ strengths are obtained at fines content of $20 \%$, which are about $30 \%$ and $18 \%$ higher than the control, respectively. However, although $3 \mathrm{~d}$ compressive strength of C60 CSC increases with fines content from 3 to $15 \%, 28 \mathrm{~d}$ compressive strength begins to decrease after achieving a maximum strength at $7 \%$. The maximum $3 \mathrm{~d}$ and $28 \mathrm{~d}$ compressive strengths of C60 CSC are about $14 \%$ and $11 \%$ higher than the control, which are lower 
TABLE 3: Concrete mix proportions and strengths of resultant concrete.

\begin{tabular}{|c|c|c|c|c|c|c|c|c|c|}
\hline \multirow[t]{2}{*}{ Strength grade } & \multirow[t]{2}{*}{ Fines content } & \multicolumn{6}{|c|}{ Unit weight $\left(\mathrm{kg} / \mathrm{m}^{3}\right)$} & \multicolumn{2}{|c|}{$\begin{array}{c}\text { Compressive strength } \\
(\mathrm{MPa})\end{array}$} \\
\hline & & Cement & Water & $\mathrm{CA}$ & $\mathrm{CS}(\mathrm{DL})$ & Fines & WR & $3 \mathrm{~d}$ & $28 \mathrm{~d}$ \\
\hline \multirow{5}{*}{$\mathrm{C} 30$} & Control & 327 & 180 & 1079 & 814 & 0 & 0.59 & 21.3 & 38.1 \\
\hline & $5 \%$ & 327 & 180 & 1079 & 773.3 & 40.7 & 0.65 & 23.8 & 39.0 \\
\hline & $10 \%$ & 327 & 180 & 1079 & 732.6 & 81.4 & 0.65 & 25.6 & 41.3 \\
\hline & $15 \%$ & 327 & 180 & 1079 & 691.9 & 122.1 & 0.65 & 27.4 & 43.3 \\
\hline & $20 \%$ & 327 & 180 & 1079 & 651.2 & 162.8 & 0.65 & 27.7 & 44.9 \\
\hline \multirow{5}{*}{ C60 } & Control & 531 & 170 & 1061 & 738 & 0 & 1.86 & 52.1 & 71.1 \\
\hline & $3 \%$ & 531 & 170 & 1061 & 715.9 & 22.1 & 2.06 & 52.7 & 76.1 \\
\hline & $7 \%$ & 531 & 170 & 1061 & 686.3 & 51.7 & 2.06 & 57.8 & 78.9 \\
\hline & $10 \%$ & 531 & 170 & 1061 & 664.2 & 73.8 & 2.06 & 58.8 & 77.7 \\
\hline & $15 \%$ & 531 & 170 & 1061 & 627.3 & 110.7 & 2.06 & 59.4 & 72.9 \\
\hline
\end{tabular}

than the strength improvement of C30 CSC. The increase of strength can be attributed to filler effect and acceleration effect on cement hydration of fines $[18,19]$.

The influences of fines content on frost durability of C30 and C60 CSC are shown in Figures 1 and 2. In Figure 1, $E_{r}$ and DF of C30 CSC under variable FT cycles decrease with increasing fines content and the trend is prominent when fines content reaches $10 \%$. C30 CSC containing $20 \%$ fines has the lowest DF which is $68 \%$ lower than the control, indicating increase of fines content significantly decreases frost durability of C30 CSC. This result is consistent with the finding of Tsivilis et al. [20], who reported that increasing incorporation of limestone fines reduced frost durability of concrete with a high W/C. It should be noted that frost durability grades of all C30 CSC are within F50-F150, which implies frost durability of C30 CSC is rather poor. Therefore, air-entraining agent is expected to improve frost durability of low-strength CSC exposed to freezing environment.

In Figure 2, $E_{r}$ and DF of C60 CSC under variable FT cycles nearly remain unchanged with increase of fines content, and they present a slight decrease when fines content rises to $10 \%$. For example, the lowest DF of C60 CSC containing $15 \%$ fines is only $3 \%$ lower than the control. Besides, $E_{r}$ of all C60 CSC after 300 FT cycles vary from $92.3 \%$ to $95.7 \%$, which can be classified as a high frost durability grade of over F300. This demonstrates that fines have little negative influence on frost durability of C60 CSC.

Fines belong to a kind of nonpozzolanic filler. The increase of fines content decreases the relative amount of cement in powdery materials of concrete, so that there is not enough cement paste to coat and bind the all aggregates [3]; thus the frost durability is compromised. For instance, when fines content increases from $0 \%$ to $10 \%$, volume percentage of cement in powdery materials in C30 concrete considerably drops from $100 \%$ to $79 \%$, whereas that in C60 concrete decreases from $100 \%$ to $90 \%$.

Frost durability of C30 CSC is inherently poor owning to high W/C. Additionally, cement content of C30 CSC is relatively low. Thus inclusion of fines significantly decreases the relative amount of cement and thereby reduces frost durability. However, C60 CSC has high frost durability due to low W/C and high cement content, which cause frost durability of C60 CSC to be much less sensitive to variation in fines content as compared to that of C30 CSC.

3.2. Influence of $M B$ Value of CS on Strength and Frost Durability. MB value of CS was adjusted by incorporating clay as partial replacements of fines at fixed fines content of $10 \%$. Concrete mix proportions and compressive strengths are shown in Table 4, and frost durability of C30 and C60 CSC is depicted in Figures 5 and 6, respectively.

As can be seen in Table 4, the maximum compressive strengths of C30 CSC at 3 days and 28 days are achieved at $\mathrm{MB}$ value of 1.0 , which are $24 \%$ and $17 \%$ higher than the control, and beyond 1.0 the compressive strengths begin to decrease. It is also noticeable that compressive strengths of all C30 concrete samples are higher than the control, which illustrates increase of $\mathrm{MB}$ value does not negatively affect strength of C30 CSC. Similar results were obtained previously by Courard et al. [2], who reported no strength reduction was found when certain amount of clay was incorporated in a mortar with W/C of 0.67 .

However, in the case of C60 CSC, compressive strengths decrease with increase of $\mathrm{MB}$ value from 0.3 to 2.0 , and they become lower than the control when $\mathrm{MB}$ value exceeds 1.0, which varies from the influence of $\mathrm{MB}$ value on compressive strength of C30 CSC. The minimum compressive strengths of $3 \mathrm{~d}$ and $28 \mathrm{~d}$ are observed at $\mathrm{MB}$ value of 2.0, which are about $7 \%$ and $10 \%$ lower than the control.

C30 concrete is vulnerable to segregation and bleeding for its high $\mathrm{W} / \mathrm{C}$ and low cement content. Inclusion of fines containing clay enhances cohesiveness of fresh concrete and fills in the voids in hardened concrete, which may create a denser matrix and thus improve strength (Figure 3). Nevertheless, for C60 concrete with low W/C, clay may not only prevent cement hydration due to absorbing free 


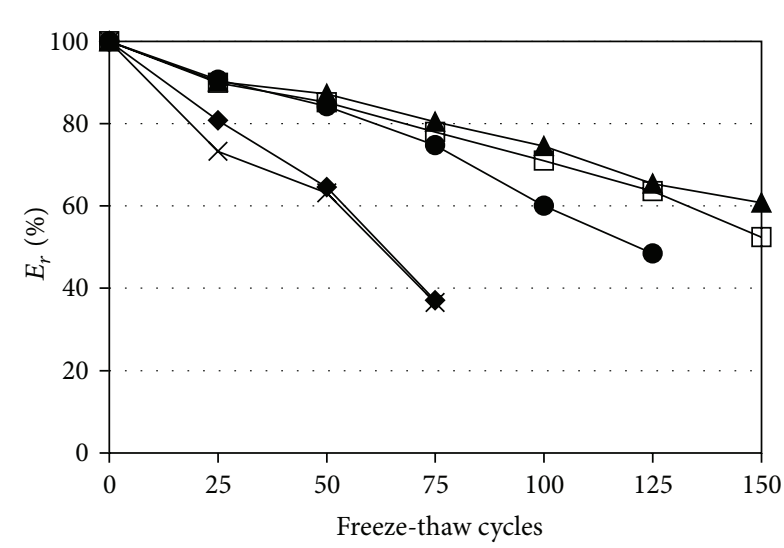

$\begin{array}{ll}\square \text { Control } & \rightarrow-15 \% \\ \rightarrow 5 \% & \rightarrow \quad 20 \% \\ \rightarrow-10 \% & \end{array}$

(a)

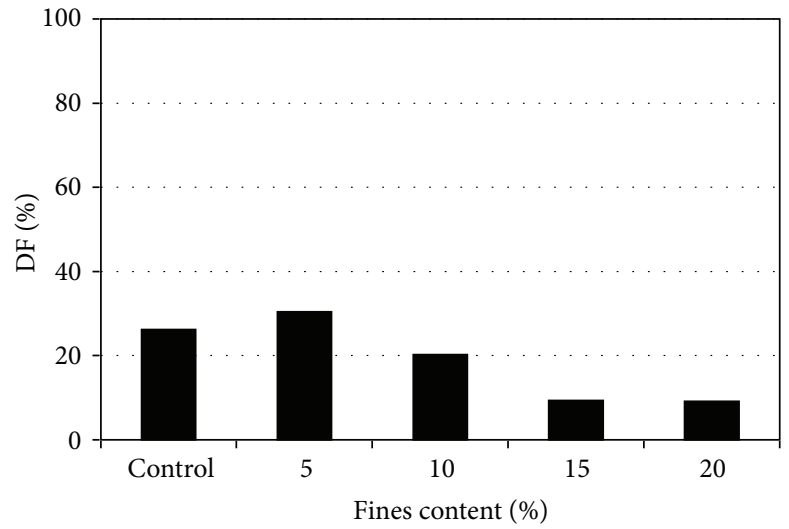

(b)

FIgURE 1: Effect of fines content on frost durability of C30 CSC: (a) $E_{r}$. (b) DF.

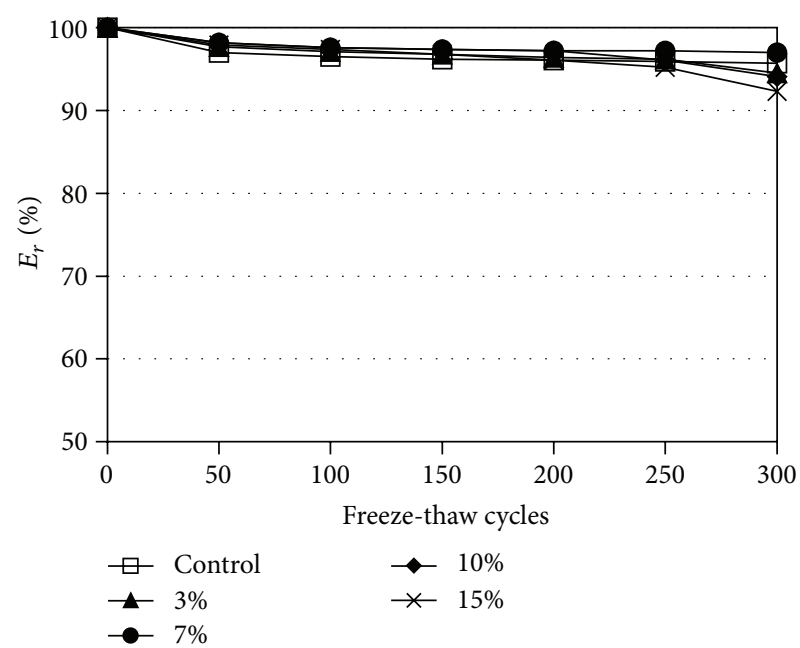

(a)

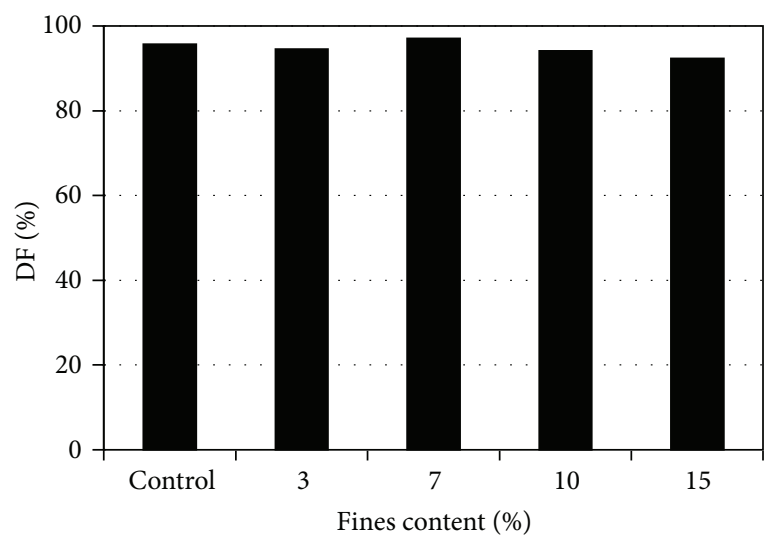

(b)

FIgURE 2: Effect of fines content on frost durability of C60 CSC: (a) $E_{r}$. (b) DF.

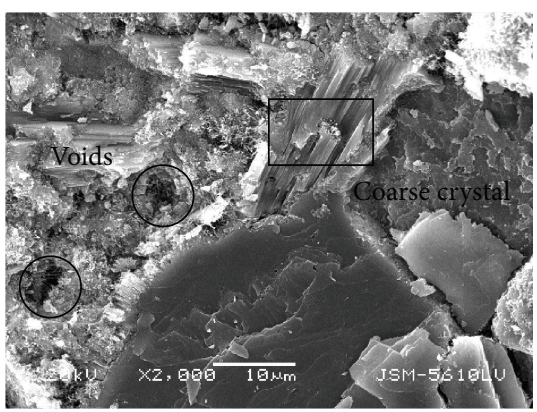

(a)

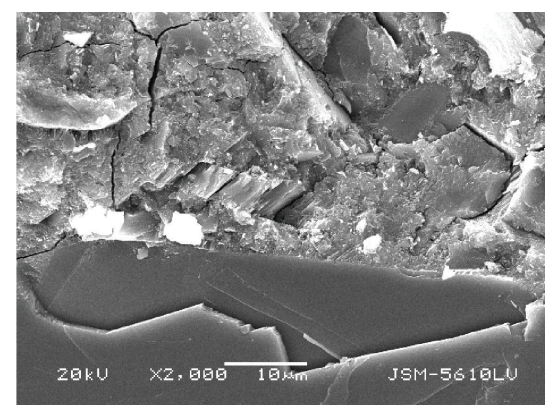

(b)

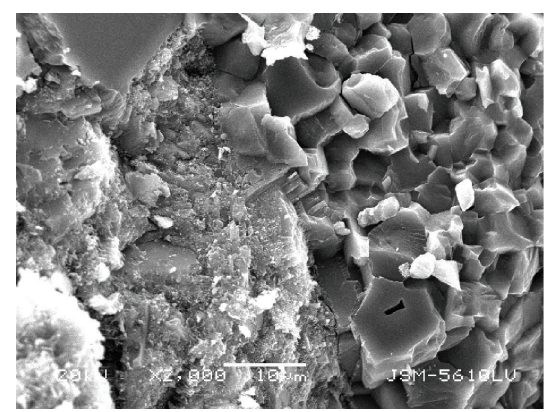

(c)

FIgure 3: SEM images of ITZ in C30 CSC: (a) the control; (b) MB value 1.0; (c) MB value 2.0. 
TABLE 4: Concrete mix proportions and strengths of resultant concrete.

\begin{tabular}{|c|c|c|c|c|c|c|c|c|c|c|c|}
\hline \multirow[t]{2}{*}{ Strength grade } & \multirow{2}{*}{$\begin{array}{c}\text { MB value } \\
(\mathrm{g} / \mathrm{kg})\end{array}$} & \multicolumn{6}{|c|}{ Unit weight $\left(\mathrm{kg} / \mathrm{m}^{3}\right)$} & \multicolumn{3}{|c|}{$\begin{array}{l}\text { Compressive } \\
\text { strength }(\mathrm{MPa})\end{array}$} & \multirow[t]{2}{*}{ WA $(\%$} \\
\hline & & Cement & Water & $\mathrm{CA}$ & $\mathrm{CS}(\mathrm{DL})$ & Fines & Clay & WR & $3 \mathrm{~d}$ & $28 \mathrm{~d}$ & \\
\hline \multirow{6}{*}{ C30 } & Control & 327 & 180 & 1079 & 814 & 0 & 0 & 0.59 & 21.3 & 38.1 & 0.96 \\
\hline & 0.3 & 327 & 180 & 1079 & 773.3 & 81.4 & 0 & 0.65 & 25.6 & 41.3 & 0.94 \\
\hline & 0.5 & 327 & 180 & 1079 & 773.3 & 79.9 & 1.5 & 0.65 & 25.9 & 43.7 & 0.93 \\
\hline & 1.0 & 327 & 180 & 1079 & 773.3 & 76.3 & 5.1 & 0.65 & 26.3 & 44.6 & 0.97 \\
\hline & 1.4 & 327 & 180 & 1079 & 773.3 & 73.6 & 7.8 & 0.65 & 26.2 & 44.3 & 1.01 \\
\hline & 2.0 & 327 & 180 & 1079 & 773.3 & 69.9 & 11.5 & 0.65 & 26.0 & 43.9 & 1.05 \\
\hline \multirow{6}{*}{ C60 } & Control & 531 & 170 & 1061 & 738 & 0 & 0 & 1.86 & 52.1 & 71.1 & 0.63 \\
\hline & 0.3 & 531 & 170 & 1061 & 664.2 & 73.8 & 0 & 2.06 & 58.8 & 77.7 & 0.60 \\
\hline & 0.5 & 531 & 170 & 1061 & 664.2 & 72.4 & 1.4 & 2.06 & 58.0 & 72.4 & 0.61 \\
\hline & 1.0 & 531 & 170 & 1061 & 664.2 & 69.2 & 4.7 & 2.06 & 53.1 & 71.7 & 0.67 \\
\hline & 1.4 & 531 & 170 & 1061 & 664.2 & 66.7 & 7.1 & 2.06 & 52.0 & 65.9 & 0.80 \\
\hline & 2.0 & 531 & 170 & 1061 & 664.2 & 63.4 & 10.4 & 2.06 & 48.5 & 64.0 & 0.97 \\
\hline
\end{tabular}

TABLE 5: Concrete mix proportions and strengths of resultant concrete.

\begin{tabular}{|c|c|c|c|c|c|c|c|c|c|}
\hline \multirow[t]{2}{*}{ Strength grade } & \multirow[t]{2}{*}{ Lithology } & \multicolumn{6}{|c|}{ Unit weight $\left(\mathrm{kg} / \mathrm{m}^{3}\right)$} & \multicolumn{2}{|c|}{$\begin{array}{c}\text { Compressive } \\
\text { strength }(\mathrm{MPa})\end{array}$} \\
\hline & & Cement & Water & CA & Sand & Fines & WR & $3 \mathrm{~d}$ & $28 \mathrm{~d}$ \\
\hline \multirow{6}{*}{$\mathrm{C} 30$} & RS & 327 & 180 & 1079 & 814 & 0 & 0.59 & 20.1 & 37.4 \\
\hline & DL & 327 & 180 & 1079 & 814 & 0 & 0.59 & 21.3 & 38.1 \\
\hline & LS & 327 & 180 & 1079 & 814 & 0 & 0.59 & 21.9 & 39.2 \\
\hline & GR & 327 & 180 & 1079 & 814 & 0 & 0.59 & 21.6 & 40.3 \\
\hline & BA & 327 & 180 & 1079 & 814 & 0 & 0.59 & 22.6 & 40.1 \\
\hline & QZ & 327 & 180 & 1079 & 814 & 0 & 0.59 & 20.3 & 38.9 \\
\hline \multirow{6}{*}{ C60 } & RS & 531 & 170 & 1061 & 738 & 0 & 1.86 & 50.5 & 69.9 \\
\hline & $\mathrm{DL}$ & 531 & 170 & 1061 & 738 & 0 & 1.86 & 52.1 & 71.1 \\
\hline & LS & 531 & 170 & 1061 & 738 & 0 & 1.86 & 53.5 & 72.9 \\
\hline & GR & 531 & 170 & 1061 & 738 & 0 & 1.86 & 55.7 & 75.8 \\
\hline & BA & 531 & 170 & 1061 & 738 & 0 & 1.86 & 54.9 & 74.8 \\
\hline & QZ & 531 & 170 & 1061 & 738 & 0 & 1.86 & 53.9 & 72.8 \\
\hline
\end{tabular}

water, but also generate voids in hardened cement paste or microcracks in interface transition zone (ITZ) [21, 22] after shrinking (Figure 4). In turn, the strength is impaired.

Influences of $\mathrm{MB}$ value on $E_{r}$ and $\mathrm{DF}$ of $\mathrm{C} 30$ and $\mathrm{C} 60$ CSC are shown in Figures 5 and 6, respectively. It is apparent that $E_{r}$ and DF of both C30 and C60 CSC under variable FT cycles decrease with increasing $\mathrm{MB}$ value, and the decrease is more pronounced when $\mathrm{MB}$ value exceeds 1.0. When $\mathrm{MB}$ value increases from 0.3 to 2.0 , frost durability grade of $\mathrm{C} 30$ CSC decreases from F125 to F25 (DF drops from 30.4\% to $8.0 \%$ relevantly), while that of C60 CSC decreases from over F300 to F200 (DF drops from $95.7 \%$ to $47.2 \%$ relevantly). This indicates increase of $\mathrm{MB}$ value significantly deteriorates frost durability of C30 and C60 CSC.

$\mathrm{MB}$ value of CS reflects the relative amount of clay in fines, and an increase of $\mathrm{MB}$ value indicates increasing amount of clay in concrete $[1,2]$. Consequently, it is supposed that clay accounts for reduction of frost durability. Firstly, clay particles expand after absorbing water in fresh concrete and later shrink to leave voids in hardened concrete, which generates higher porosity and thus decreases strength and impermeability and, secondly, dehydrated clay particles will absorb water again in water-saturated environment, both of which result in a higher water absorption (WA, as seen in Table 4) and increase saturation degree of concrete. Saturation degree is found to be the key factor affecting frost durability [23]. Hence the frost damage is exaggerated during FT cycles, and the higher the MB value of CS is, the greater the frost durability is reduced.

3.3. Influence of Lithology of CS on Strength and Frost Durability. One RS and five CSs of different lithologies were selected to prepare concrete according to mix proportions in Table 5. The influences of CS lithology on compressive strength and frost durability of CSC were studied, and the 


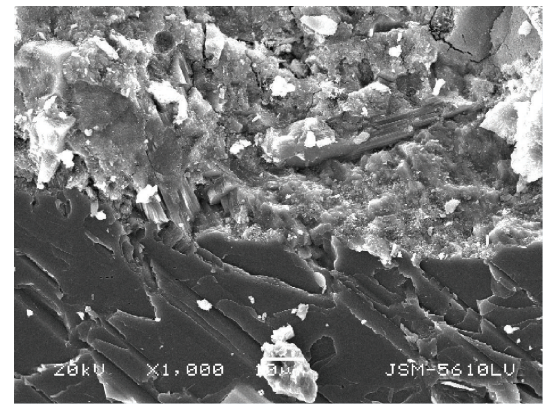

(a)

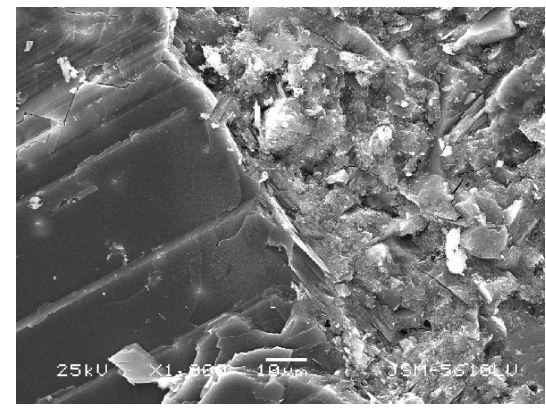

(b)

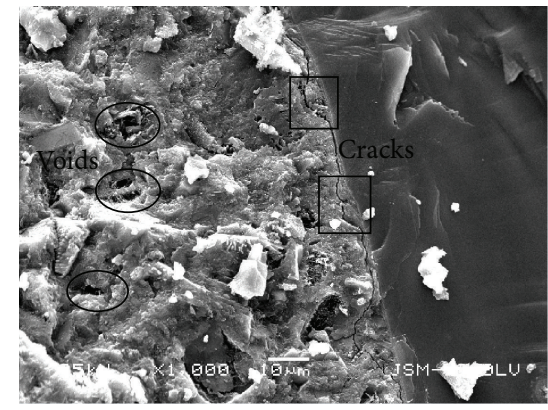

(c)

Figure 4: SEM images of ITZ in C60 CSC: (a) the control; (b) MB value 1.0; (c) MB value 2.0.

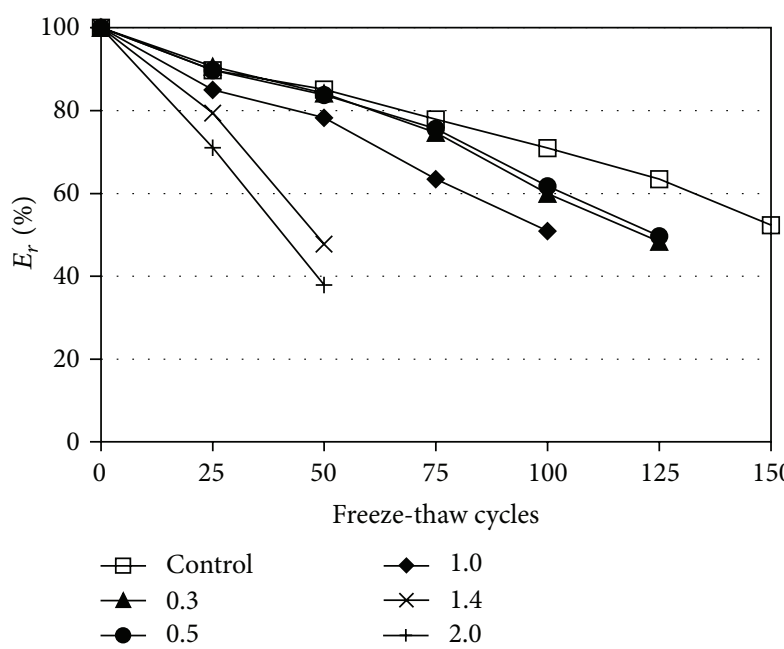

(a)

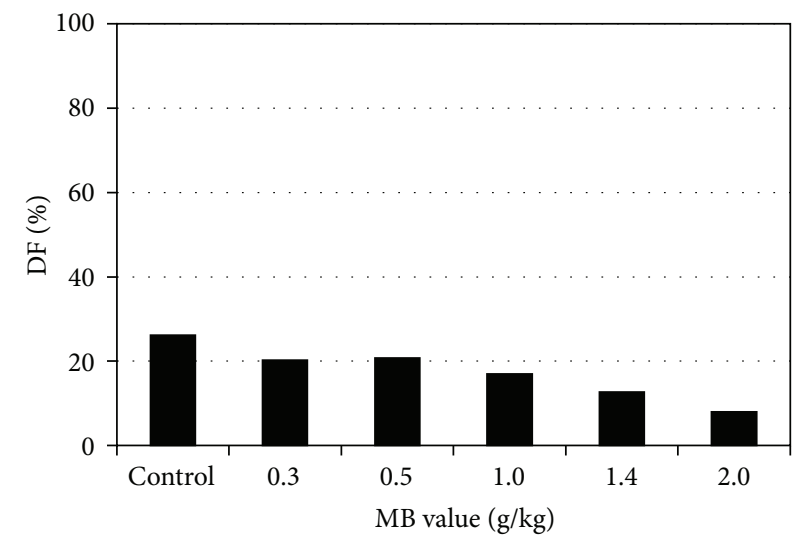

(b)

Figure 5: Effect of MB value on frost durability of C30 CSC: (a) $E_{r}$. (b) DF.

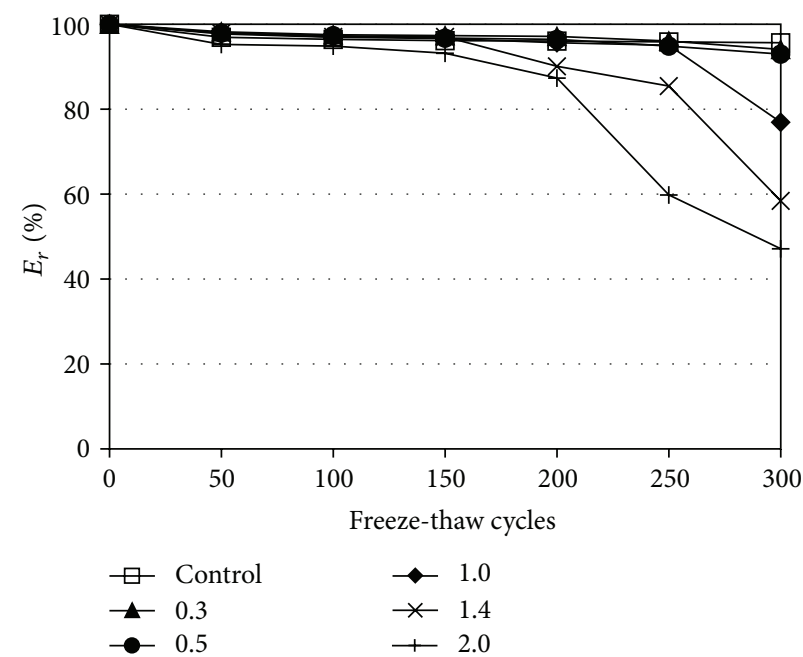

(a)

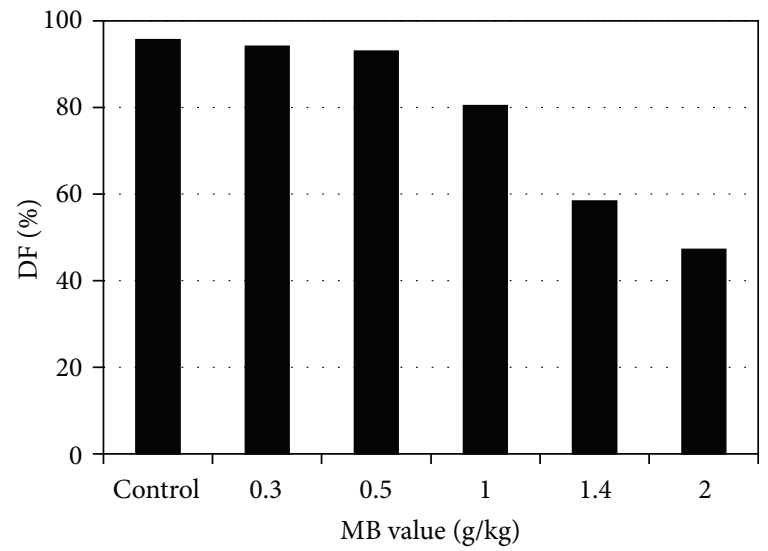

(b)

FIGURE 6: Effect of MB value on frost durability of C60 CSC: (a) $E_{r}$. (b) DF. 


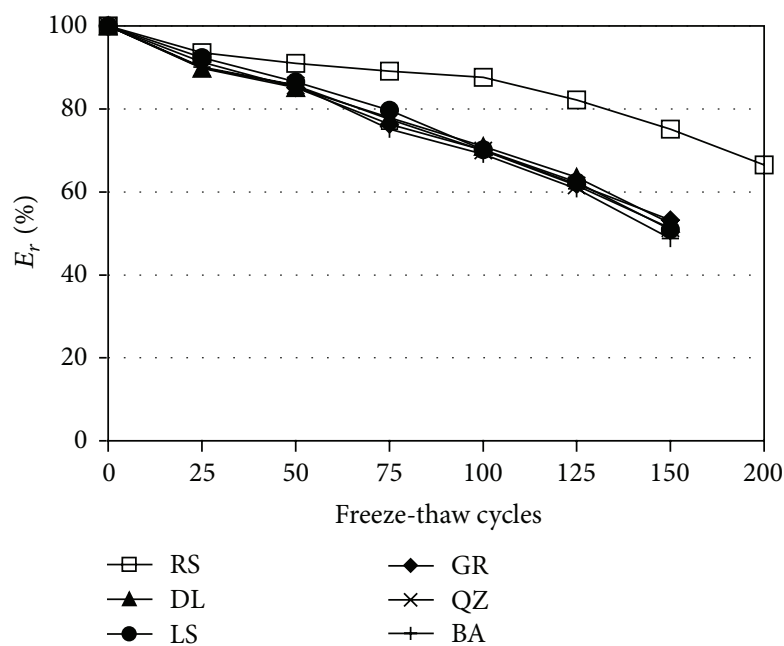

(a)

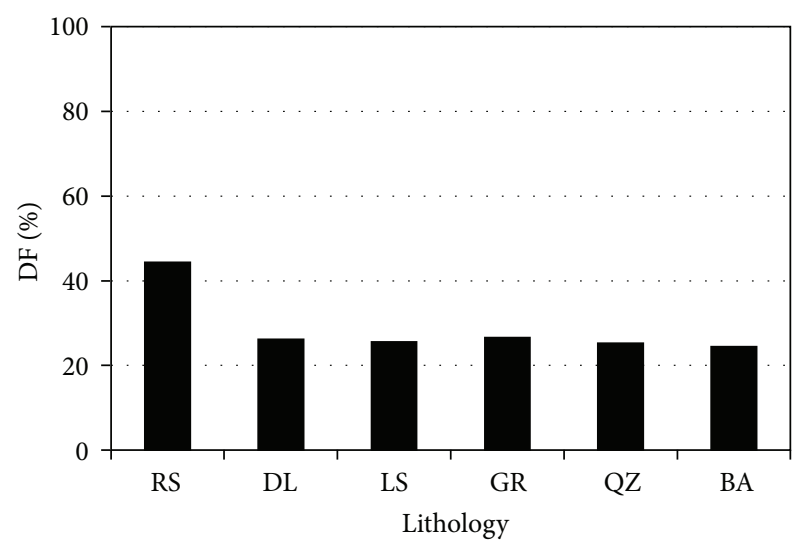

(b)

FIGURE 7: Effect of lithology on frost durability of C30 concrete: (a) $E_{r}$. (b) DF.

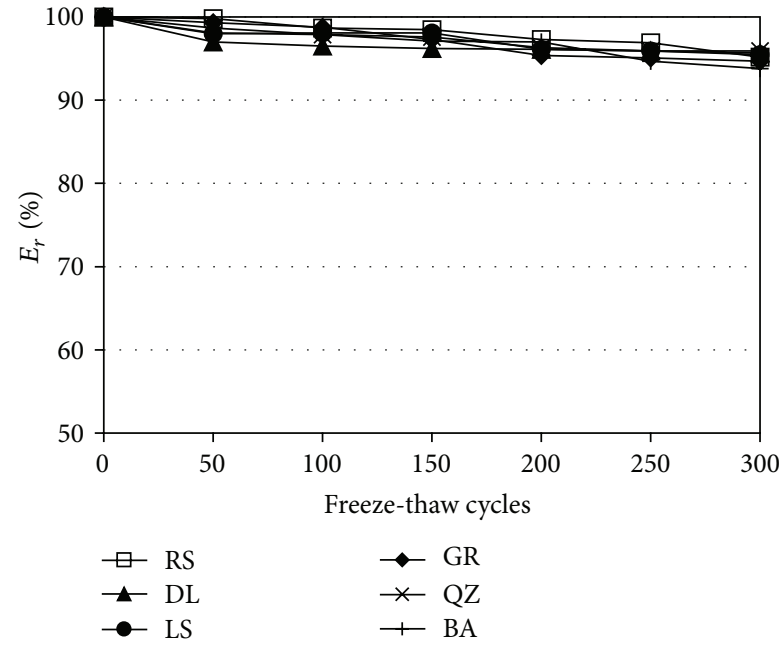

(a)

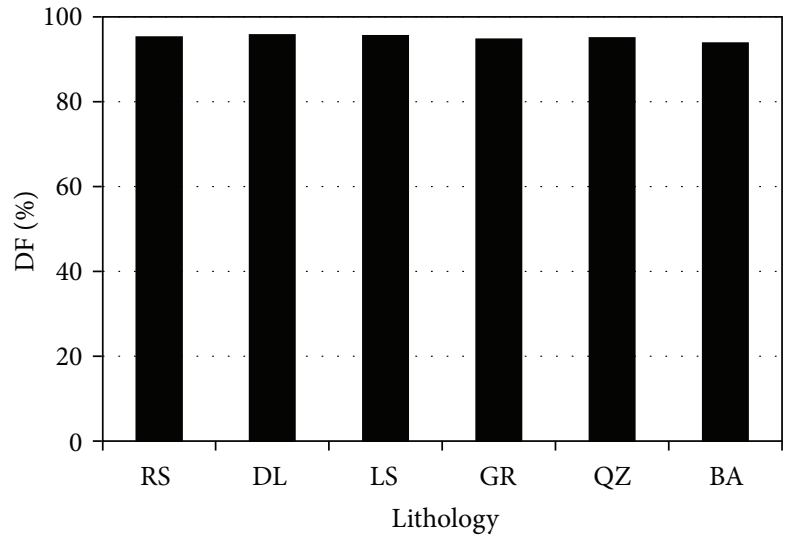

(b)

FIGURE 8: Effect of lithology on frost durability of C60 concrete: (a) $E_{r}$. (b) DF.

frost durability between CSC and RSC with equal W/C was compared.

As shown in Table 5, $28 \mathrm{~d}$ compressive strengths of C30 and C60 concrete made with various CSs are within range of 38.1-40.3 MPa and 71.1-75.8 MPa. It can be calculated that the variation coefficient of strength is around $2 \%$, which indicates CS lithology seems to have little impact on compressive strength of C30 and C60 CSC. However, concrete made with granite CS presents relatively higher strength than the other groups. This is probably due to the fact that granite CS particles have higher mechanical strength (lower crushing value) than the others, which increases the mechanical interlocking with cement paste [24]. In addition, the average $28 \mathrm{~d}$ compressive strength of CSC is about $5 \%$ higher than that of RSC. This can be attributed to the fact that CS particles have tougher surface texture and more angular shape, which enables them to have stronger bonding with cement paste than RS particles do [6, 11].

The influences of lithology on $E_{r}$ and DF of C30 and C60 concrete are shown in Figures 7 and 8. In Figure 7, $E_{r}$ of C30 concrete prepared with CS of different lithologies are not below $60 \%$ until FT cycle number reaches 125 , while $E_{r}$ of all C60 concrete samples are above $90 \%$ after 300 FT cycles. This illustrates that frost durability grade of all C30 CSC is F125 while that of all C60 CSC is over F300. Moreover, the DF differences among C30 CSC and C60 CSC are less than 2\% which is nearly negligible. Therefore, it can be stated that CS lithology has no prominent influence on strength and frost durability within the lithologies studied.

Figures 7 and 8 show that frost durability grades of C30 CSC and RSC are, respectively, F125 and F200, and DF of C30 CSC is $42 \%$ lower than that of C30 RSC. However, 
no remarkable difference is noticed between frost durability grade and DF of C60 CSC and RSC. This manifests that frost durability of C60 CSC is nearly equal to that of C60 RSC, whereas frost durability of C30 CSC is much poorer than that of C30 RSC. This could be due to the fact that microcracks are likely generated on surface of CS particles after crushing $[9,10]$, which results in water absorption and crushing value of CS particles being much higher than those of RS particles. According to the data in Table 2, water absorption and crushing value of the used RS are $0.53 \%$ and $12.4 \%$, and the average water absorption and crushing value of studied CS are $0.95 \%$ and $21.4 \%$, which are nearly twice as high as those of RS particles.

For C30 concrete with low strength and impermeability, CS particles with high crushing value (low mechanical strength) and water absorption (high permeability), together with the interface between sand particle and cement paste, might be damaged by freezing of water penetrated into concrete, which leads to frost durability of C30 CSC being reduced and poorer than that of C30 RSC. However, as for C60 concrete having high strength and impermeability, the sand particles are so well bonded by cement paste that neither the sand particle nor interface could be frozen to damage. Thus, frost durability of C60 CSC is rarely affected and nearly equal to that of C60 RSC.

Crushing values and water absorptions of the used CS are almost around $20 \%$ and $0.9 \%$, respectively, which may account for inconspicuous frost durability difference of concrete prepared with CS of various lithologies. Parent rock lithology can affect water absorption and crushing value of $\mathrm{CS}$, and some researcher believed they were related to frost durability of concrete $[25,26]$. Therefore, in the next stage of study, more representative CS samples should be selected to investigate the effect of water absorption and crushing value of CS on frost durability.

\section{Conclusion}

Based on the experimental results of this research, the following conclusions can be drawn:

(1) Increasing fines content of dolomite CS improves concrete strength and reduces frost durability of C30 CSC when fines content reaches $10 \%$. However, it has little negative effect on frost durability of C60 CSC.

(2) Increasing MB value of dolomite CS does not negatively affect strength of C30 CSC but decreases strength of C60 CSC and frost durability of CSC, and the reduction is more pronounced when $\mathrm{MB}$ value exceeds 1.0.

(3) CS lithology has no prominent influence on frost durability and strength of CSC within the lithologies studied.

(4) Compressive strength of CSC is a little higher than RSC under equal W/C, yet frost durability of CSC is no better than RSC especially for C30 CSC.

(5) To ensure frost durability of CSC, fines content and $\mathrm{MB}$ value of CS should be limited to be less than
$10 \%$ and 1.0. Air-entraining agent is suggested for enhancing frost durability of C30 CSC exposed to freezing environment.

\section{Competing Interests}

The authors declare that there are no competing interests regarding the publication of this paper.

\section{References}

[1] J. K. Norvell, J. G. Stewart, M. C. G. Juenger, and D. W. Fowler, "Influence of clays and clay-sized particles on concrete performance," Journal of Materials in Civil Engineering, vol. 19, no. 12, pp. 1053-1059, 2007.

[2] L. Courard, F. Michel, and J. Pierard, "Influence of clay in limestone fillers for self-compacting cement based composites," Construction and Building Materials, vol. 25, no. 3, pp. 13561361, 2011.

[3] B. Li, J. Wang, and M. Zhou, "Effect of limestone fines content in manufactured sand on durability of low- and high-strength concretes," Construction and Building Materials, vol. 23, no. 8, pp. 2846-2850, 2009.

[4] P. N. Quiroga, N. Ahn, and D. W. Fowler, "Concrete mixtures with high microfines," ACI Materials Journal, vol. 103, no. 4, pp. 258-264, 2006.

[5] I. B. Topçu and A. Ugurlu, "Effect of the use of mineral filler on the properties of concrete," Cement and Concrete Research, vol. 33, no. 7, pp. 1071-1075, 2003.

[6] J. P. Gonçalves, L. M. Tavares, R. D. Toledo Filho, E. M. R. Fairbairn, and E. R. Cunha, "Comparison of natural and manufactured fine aggregates in cement mortars," Cement and Concrete Research, vol. 37, no. 6, pp. 924-932, 2007.

[7] H. Li, F. Huang, G. Cheng et al., "Effect of granite dust on mechanical and some durability properties of manufactured sand concrete," Construction and Building Materials, vol. 109, pp. 41-46, 2016.

[8] Z. Liu and M. Zhou, "Properties of low- and high-strength concrete incorporating clay-contaminated microfines," Arabian Journal for Science and Engineering, vol. 41, no. 2, pp. 443-450, 2016.

[9] R. Cepuritis, S. Jacobsen, and T. Onnela, "Sand production with VSI crushing and air classification: optimising fines grading for concrete production with micro-proportioning," Minerals Engineering, vol. 78, pp. 1-14, 2015.

[10] M. S. Guimaraes, J. R. Valdes, A. M. Palomino, and J. C. Santamarina, "Aggregate production: fines generation during rock crushing," International Journal of Mineral Processing, vol. 81, no. 4, pp. 237-247, 2007.

[11] J.-K. Kim, C.-S. Lee, C.-K. Park, and S.-H. Eo, "The fracture characteristics of crushed limestone sand concrete," Cement and Concrete Research, vol. 27, no. 11, pp. 1719-1729, 1997.

[12] B. Menadi, S. Kenai, J. Khatib, and A. Ait-Mokhtar, "Strength and durability of concrete incorporating crushed limestone sand," Construction and Building Materials, vol. 23, no. 2, pp. 625-633, 2009.

[13] Code of China, "Polycarboxylates high performance waterreducing admixture," JG/T 223-2007, Ministry of Construction of People's Republic of China, Beijing, China, 2007. 
[14] Code of China, "Test methods of aggregate for highway engineering," JTG E42-2005, Department of Transportation of People's Republic of China, Beijing, China, 2005.

[15] Code of China, "Test methods of cement and concrete for highway engineering," JTG E30-2005, Department of Transportation of People's Republic of China, Beijing, China, 2005.

[16] ASTM, "Standard test method for density, absorption, and voids in hardened concrete," ASTM C642-13, American Society for Testing and Materials, Philadelphia, Pa, USA, 2013.

[17] Code of China, "Standard for test methods of long-term performance and durability of ordinary concrete," GB/T 500902009, Ministry of Housing and Urban-Rural Development of People's Republic of China, Beijing, China, 2009.

[18] E. H. Kadri, S. Aggoun, G. D. Schutter, and K. Ezziane, "Combined effect of chemical nature and fineness of mineral powders on Portland cement hydration," Materials and Structures, vol. 43, no. 5, pp. 665-673, 2010.

[19] G. Ye, X. Liu, G. D. Schutter et al., "Influence of limestone powder used as filler in SCC on hydration and microstructure of cement paste," Cement and Concrete Composites, vol. 29, no. 2, pp. 94-102, 2007.

[20] S. Tsivilis, G. Batis, E. Chaniotakis, G. Grigoriadis, and D. Theodossis, "Properties and behavior of limestone cement concrete and mortar," Cement and Concrete Research, vol. 30, no. 10, pp. 1679-1683, 2000.

[21] I. B. Topçu and A. Demir, "Relationship between methylene blue values of concrete aggregate fines and some concrete properties," Canadian Journal of Civil Engineering, vol. 35, no. 4, pp. 379-383, 2008.

[22] B. Felekoğlu, "A comparative study on the performance of sands rich and poor in fines in self-compacting concrete," Construction and Building Materials, vol. 22, no. 4, pp. 646-654, 2008.

[23] G. Fagerlund, "The critical degree of saturation method of assessing the freeze/thaw resistance of concrete," Materials and Structures, vol. 10, no. 58, pp. 379-382, 1977.

[24] H. Donza, O. Cabrera, and E. F. Irassar, "High-strength concrete with different fine aggregate," Cement and Concrete Research, vol. 32, no. 11, pp. 1755-1761, 2002.

[25] P. K. Mehta and P. J. Monteiro, Concrete: Microstructure, Properties, and Materials, McGraw-Hill, New York, NY, USA, 2006.

[26] G. Verbeck and R. Landgren, "Influence of physical characteristics of aggregates on frost resistance of Concrete," in Proceedings of the American Society for Testing and Materials (ASTM '96), vol. 60, pp. 1063-1079, ASTM, Philadelphia, Pa, USA, 1996. 

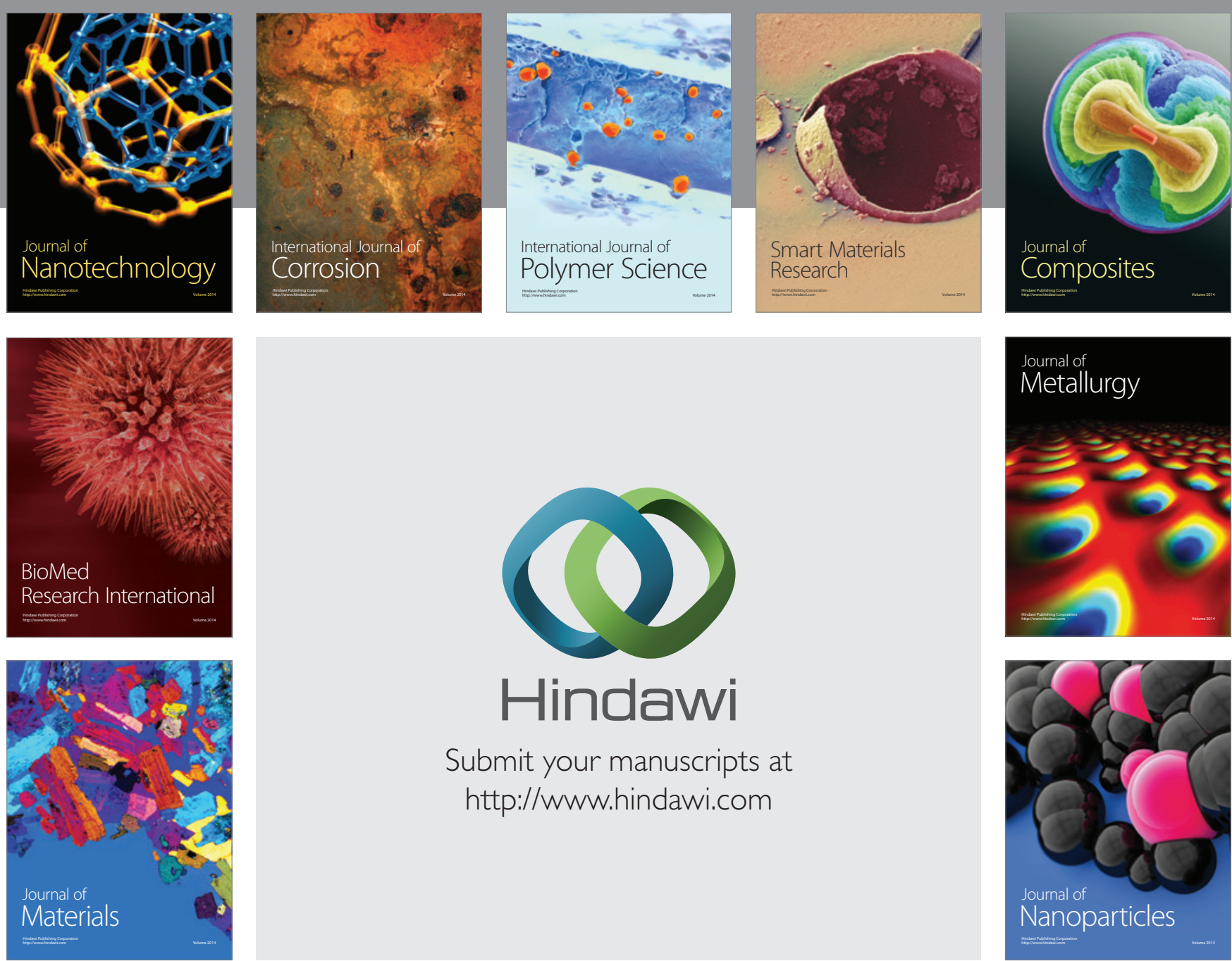

\section{Hindawi}

Submit your manuscripts at

http://www.hindawi.com

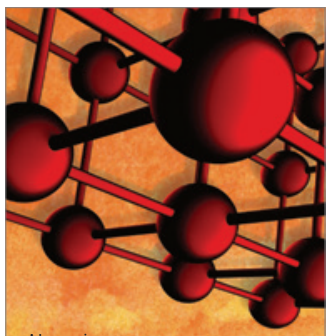

Materials Science and Engineering
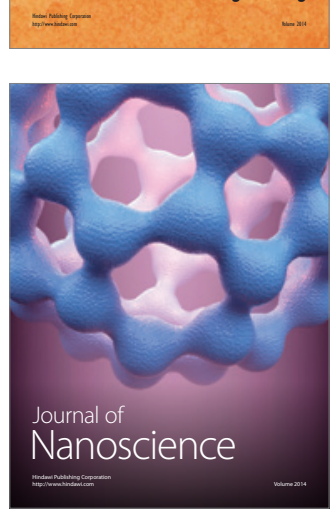
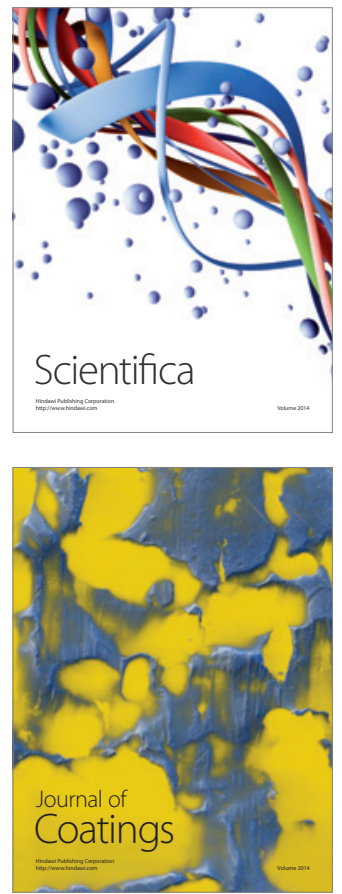
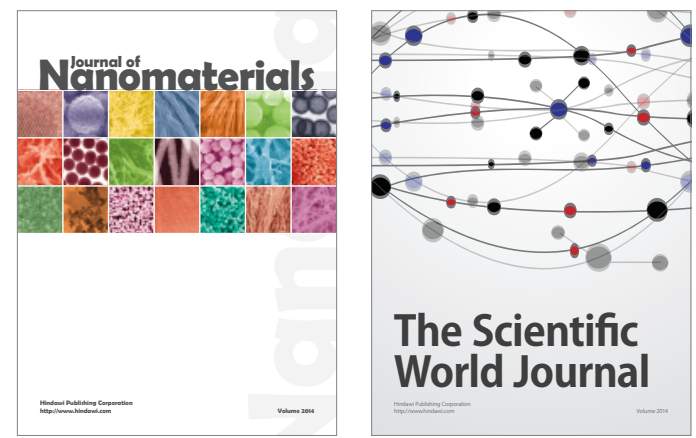

The Scientific World Journal
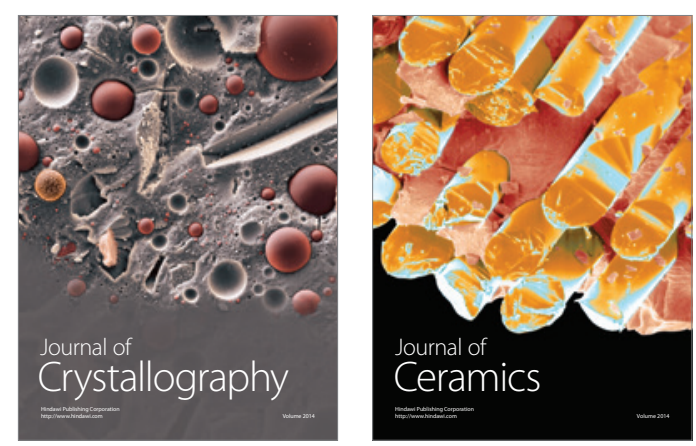
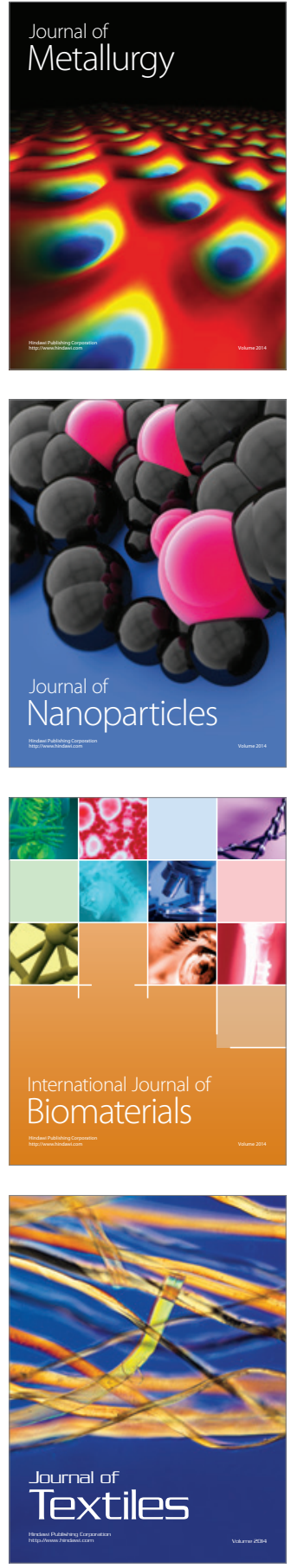